\title{
Critical adjustment of land mitigation pathways for assessing countries' climate progress
}

\author{
Giacomo Grassi ${ }^{1 凶}$, Elke Stehfest ${ }^{2}{ }^{2}$, Joeri Rogelj ${ }^{3,4}$, Detlef van Vuuren ${ }^{2,5}$, Alessandro Cescatti ${ }^{1}$, \\ Jo House $\mathbb{1}^{6}$, Gert-Jan Nabuurs $\mathbb{1}^{7}$, Simone Rossi', Ramdane Alkama ${ }^{1}{ }^{1}$, Raúl Abad Viñas', \\ Katherine Calvin ${ }^{8}{ }^{8}$, Guido Ceccherini ${ }^{\circledR 1}$, Sandro Federici ${ }^{\circledR}{ }^{9}$, Shinichiro Fujimori ${ }^{4,10,11}$, Mykola Gusti ${ }^{4,12}$, \\ Tomoko Hasegawa ${ }^{11,13}$, Petr Havlik ${ }^{1}{ }^{4}$, Florian Humpenöder ${ }^{14}$, Anu Korosuo', Lucia Perugini ${ }^{15}$, \\ Francesco N. Tubiello (1) ${ }^{16}$ and Alexander Popp ${ }^{14}$
}

\begin{abstract}
Mitigation pathways by Integrated Assessment Models (IAMs) describe future emissions that keep global warming below specific temperature limits and are compared with countries' collective greenhouse gas (GHG) emission reduction pledges. This is needed to assess mitigation progress and inform emission targets under the Paris Agreement. Currently, however, a mismatch of $\sim 5.5 \mathrm{GtCO}_{2} \mathrm{yr}^{-1}$ exists between the global land-use fluxes estimated with IAMs and from countries' GHG inventories. Here we present a 'Rosetta stone' adjustment to translate IAMs' land-use mitigation pathways to estimates more comparable with GHG inventories. This does not change the original decarbonization pathways, but reallocates part of the land sink to be consistent with GHG inventories. Adjusted cumulative emissions over the period until net zero for 1.5 or $2{ }^{\circ} \mathrm{C}$ limits are reduced by $120-192 \mathrm{GtCO}_{2}$ relative to the original IAM pathways. These differences should be taken into account to ensure an accurate assessment of progress towards the Paris Agreement.
\end{abstract}

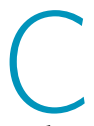
hanges in land use and land management contribute around $14 \%$ of the total global anthropogenic $\mathrm{CO}_{2}$ emissions ${ }^{1}$, mainly through deforestation. Simultaneously, terrestrial sinks-both natural and anthropogenic-absorb nearly a third of the total anthropogenic $\mathrm{CO}_{2}$ emissions ${ }^{2}$, mainly in forests. Land use, land-use change and forestry (LULUCF) measures represent about $25 \%$ of the emissions reductions pledged by countries in their National Determined Contributions (NDCs) to the Paris Agreement ${ }^{3}$. Land-based mitigation ${ }^{4,5}$ is increasingly recognized as a key strategy to reach the Paris Agreement's aim to "achieve a balance between anthropogenic emissions by sources and removals by sinks" ${ }^{\prime \prime}$, .

The Paris Agreement ${ }^{7}$ mandates a periodic global stocktake exercise, to assess countries' collective progress towards meeting its long-term goals. This exercise will take place for the first time starting in 2022 and finishing in 2023. Any identified gap between the globally aggregated reported and pledged emissions and emission pathways consistent with the Paris Agreement is expected to motivate increased mitigation ambition in subsequent NDCs (Supplementary Section 1). Monitoring of historical progress is based on national greenhouse gas inventories (NGHGIs), whereas the assessment of future actions is based on countries' climate targets (NDCs in 2025 or 2030 and long-term strategies in 2050). Estimates of the appropriate level of mitigation are based on emission pathways consistent with limiting warming to $1.5^{\circ} \mathrm{C}$ and well-below $2^{\circ} \mathrm{C}$, from models and scenarios developed by the scientific community ${ }^{8-10}$. This, however, requires that the estimates used to derive the emission pathways and the country data used to measure progress are comparable.

Countries report national historical anthropogenic land $\mathrm{CO}_{2}$ fluxes as part of the LULUCF component of the NGHGIs, which are periodically submitted to the United Nations Framework Convention on Climate Change (UNFCCC). Independent global estimates of anthropogenic land $\mathrm{CO}_{2}$ fluxes assessed by the Intergovernmental Panel on Climate Change (IPCC) $)^{1,11,12}$ are from global-scale models. In global assessments, bookkeeping models and dynamic global vegetation models (DGVMs) are used to assess historical emissions' ${ }^{2}$, and Integrated Assessment Models (IAMs) are used to explore scenarios and pathways of future changes ${ }^{9,13,14}$.

Previous studies highlighted that NGHGIs report values of global anthropogenic net $\mathrm{CO}_{2}$ emissions from land (mostly from forest land and deforestation) that are $4-5 \mathrm{GtCO}_{2} \mathrm{yr}^{-1}$ lower than those estimated by bookkeeping models and DGVMs for the period 2005-2014 (refs. ${ }^{1,15}$ ). Here we show that this large difference exists also between NGHGIs and IAMs, with an estimated $5.5 \mathrm{GtCO}_{2} \mathrm{yr}^{-1}$ gap for the period 2005-2015 (Fig. 1a). This gap represents a key barrier to the use of IAMs in helping to set adequate emission targets in the context of the Paris Agreement. This issue has been acknowledged at the highest levels, such as in the Summary for Policymakers sections of recent IPCC Special Reports (on global warming of $1.5^{\circ} \mathrm{C}\left(\right.$ ref. ${ }^{12}$ ) and on climate change and land ${ }^{1}$ ) and during a UNFCCC plenary ${ }^{16}$. A viable solution is needed by both the IPCC and the policymakers.

1Joint Research Centre, European Commission, Ispra, Italy. ${ }^{2} \mathrm{PBL}$ Netherlands Environmental Assessment Agency, the Hague, the Netherlands. ${ }^{3} \mathrm{Grantham}$ Institute for Climate Change and the Environment, Imperial College London, London, UK. ${ }^{4}$ International Institute for Applied System Analysis (IIASA), Laxenburg, Austria. ${ }^{5}$ Copernicus Institute of Sustainable Development, Utrecht University, Utrecht, the Netherlands. ${ }^{6}$ Cabot Institute, Department of Geographical Sciences, University of Bristol, Bristol, UK. ${ }^{7}$ Wageningen University and Research, Wageningen, the Netherlands. ${ }^{8}$ Pacific Northwest National Laboratory, Joint Global Change Research Institute at the University of Maryland-College Park, College Park, MD, USA. ${ }^{9}$ Institute for Global Environmental Strategies, Hayama, Japan. ${ }^{10}$ Department of Environmental Engineering, Kyoto University, Kyoto City, Japan. ${ }^{11}$ Center for Social and Environmental Systems Research, National Institute for Environmental Studies (NIES), Ibaraki, Japan. ${ }^{12}$ Lviv Polytechnic National University, Lviv, Ukraine. ${ }^{13}$ College of Science and Engineering, Ritsumeikan University, Shiga, Japan. ${ }^{14}$ Potsdam Institute for Climate Impact Research (PIK), Potsdam, Germany. ${ }^{15}$ Division on Climate Change Impacts on Agriculture, Forests and Ecosystem Services (IAFES), Foundation Euro-Mediterranean Center on Climate Change (CMCC), Viterbo, Italy. ${ }^{16} \mathrm{FAO}$ Statistics Division, Via Terme di Caracalla, Rome, Italy. 凶e-mail: giacomo.grassi@ec.europa.eu 
a
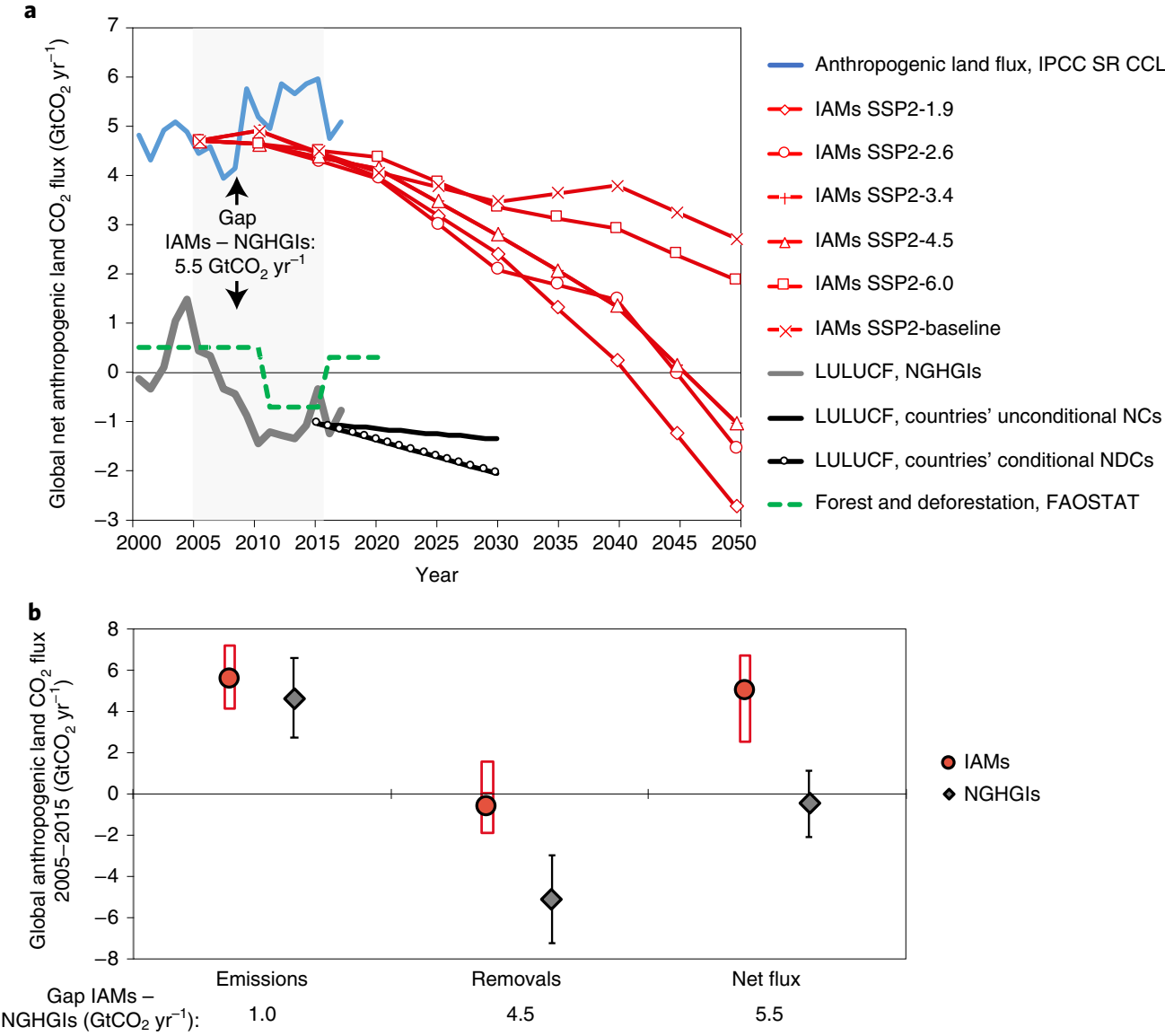

Fig. 1 | Global net anthropogenic land $\mathrm{CO}_{2}$ fluxes estimated by global models and reported in $\mathbf{N G H G l s . ~ a , ~ G l o b a l ~ n e t ~ a n t h r o p o g e n i c ~ l a n d ~} \mathrm{CO}_{2}$ flux from the IPCC Special Report on Climate Change and Land (IPPC SRCCL) (blue line, using two bookkeeping models ${ }^{47}$ ), from IAMs (averages of five models for various SSP2 mitigation scenarios ${ }^{14,48}$, red lines, starting in 2005) and from the sum of LULUCF in the NGHGIs (grey line, mostly forest sink and deforestation). Fluxes from forest and deforestation in the NGHGIs are comparable with those reported by FAOSTAT ${ }^{49}$ (green dashed line, elaborated based on country reports to Food and Agriculture Organization's Forest Resources Assessment (FAO-FRA) $2020\left(\right.$ ref. $\left.{ }^{50}\right)$ ). The sum of conditional and unconditional $\mathrm{NDCs}$ for the land-use sector ${ }^{3}$ are shown as black lines. Positive fluxes indicate net emissions, whereas negative fluxes indicate net removals of $\mathrm{CO}_{2}$ from the atmosphere. The gap between IAMs and NGHGIs is equal to $5.5 \mathrm{GtCO}_{2} \mathrm{yr}^{-1}$ for the period 2005-2015. b, Global anthropogenic land $\mathrm{CO}_{2}$ emissions (mainly from deforestation), removals (mainly forest sink) and net flux, as estimated in IAMs (average with minimum-maximum range) and by the sum of NGHGls (surrounded by a 95\% confidence interval) for the period 2005-2015. See Methods for the details.

The inconsistency between NGHGI and IAM estimates is almost entirely due to a difference in anthropogenic $\mathrm{CO}_{2}$ removals $\left(4.5 \mathrm{GtCO}_{2} \mathrm{yr}^{-1}\right.$, Fig. $\left.1 \mathrm{~b}\right)$, which mostly occur in forests. This difference is potentially a consequence of: (1) simplified and/or incomplete representations of land-use change and management in global models ${ }^{14,17}$, which includes the role of forest management in promoting biomass expansions and thickening ${ }^{18}$, and the impact of forest demography ${ }^{19}$, (2) inaccurate and/or incomplete estimation of LULUCF fluxes in NGHGIs ${ }^{3}$, especially in non-forest land uses and in soils, and (3) conceptual inconsistencies between global models and NGHGIs in estimating 'anthropogenic' $\mathrm{CO}_{2}$ fluxes from land, which mean the estimates are hardly comparable ${ }^{15}$. The impacts of (1) and (2) are difficult to quantify, and result in uncertainties that will decrease slowly over time through improvements of both the models and NGHGIs. By contrast, the inconsistencies in (3) and their resulting biases can be assessed and addressed.

The purpose of this study is to provide a means to make IAM land-use $\mathrm{CO}_{2}$ mitigation pathways more comparable with NGHGIs at the global and regional levels, with the aim to facilitate the assessment of collective progress against the Paris Agreement's mitigation goals. Extending previous studies ${ }^{15}$, we first show how the above-mentioned methodological inconsistencies cause differences in estimated global anthropogenic land $\mathrm{CO}_{2}$ fluxes. Then, we use results from five IAMs (AIM-CGE ${ }^{20}$, GCAM4 (ref. ${ }^{21}$ ), IMAGE ${ }^{13}$, MESSAGE-GLOBIOM $^{22}$ and REMIND-MAgPIE ${ }^{23}$ (Methods)) and one DGVM (LPJmL ${ }^{24}$ ) to apply a new method that, by adjusting the IAM results, ensures comparability between the IAMs and NGHGIs. Without this adjustment, country climate targets (based on the approach of NGHGIs) cannot meaningfully be assessed using the land mitigation pathways from IAMs.

\section{Different scopes led to different approaches to land-use fluxes}

The different scientific communities involved in global land-flux modelling and NGHGIs have developed independent approaches to estimate anthropogenic land $\mathrm{CO}_{2}$ fluxes, and these have different purposes and scopes. Global models focus on producing globally consistent estimates, which are assessed in IPCC reports ${ }^{1,11,12}$. Meanwhile, IPCC Guidelines for estimating NGHGIs ${ }^{25}$ focus on individual countries, aimed at pragmatic and consistent methodologies that are generally applicable. Approaches developed by both communities are valid in their own specific context. However, a meaningful comparison of anthropogenic land $\mathrm{CO}_{2}$ fluxes between them is hampered by conceptual differences in the estimation of: 
a

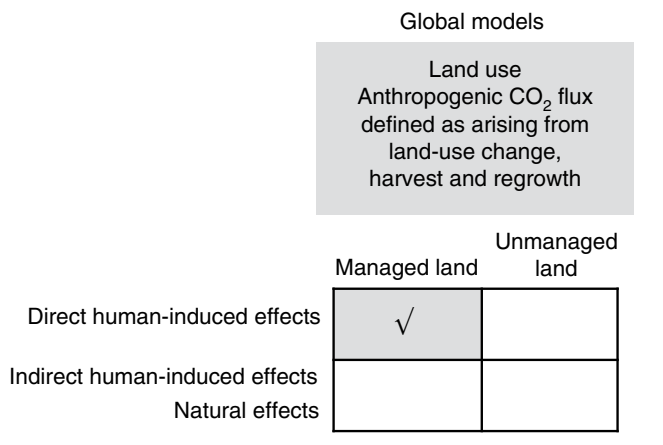

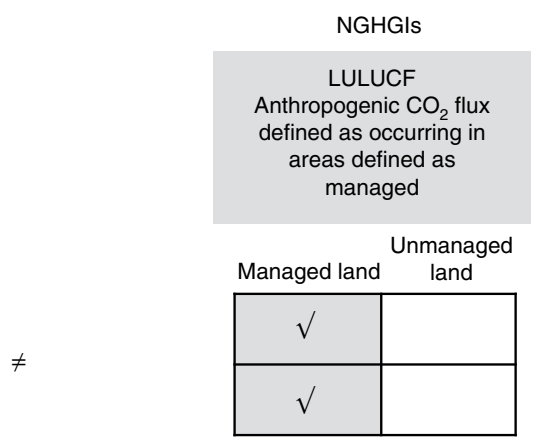

Anthropogenic $\mathrm{CO}_{2}$ flux

fined as occurring in

as defined as

Unmanaged

b

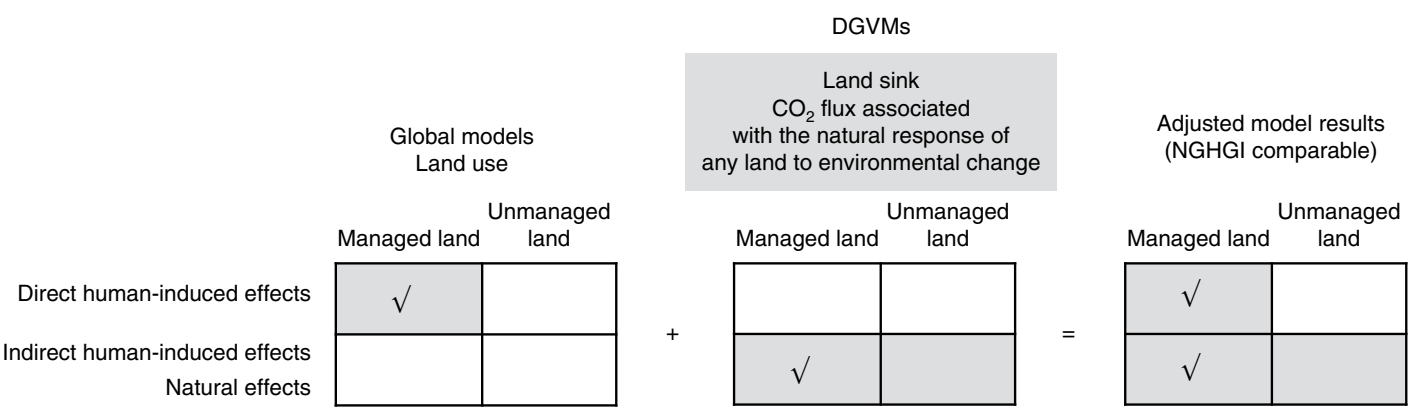

$=$ Fluxes that correspond to the text in the grey box

$\sqrt{ }=$ Considered in the comparison

Fig. 2 | Main conceptual inconsistencies between IAMs and NGHGls in estimating what is considered the anthropogenic land $\mathrm{CO}_{2}$ flux, and proposed solution. a, Differences in estimating the anthropogenic land $\mathrm{CO}_{2}$ flux by global models (land use of bookkeeping models and IAMs (left) and LULUCF of NGHGIs (right), which include the attribution of effects that influence the land $\mathrm{CO}_{2}$ flux (as defined by the IPCC ${ }^{26}$ ) in managed and unmanaged lands. The anthropogenic land $\mathrm{CO}_{2}$ flux by global models typically includes only the $\mathrm{CO}_{2}$ flux due to direct human-induced effects (land-use change, harvest and regrowth), although system boundaries make this attribution uncertain ${ }^{51}$. By contrast, NGHGIs consider anthropogenic all the fluxes that occur in areas defined as managed (Fig. 3a), and typically also include most of the sink due to indirect human-induced effects (climate change, atmospheric $\mathrm{CO}_{2}$ increase, nitrogen deposition and so on) and due to natural effects (climate variability and background natural disturbance regime). These indirect human-induced and natural effects are modelled by some IAMs (for example, via DGVMs), but are not included in the reported anthropogenic land use flux from IAMs and related IPCC Assessments. b. Proposed solution to the inconsistency, via disaggregation of the land sink flux from DGVMs (from indirect and natural effects) into the $\mathrm{CO}_{2}$ fluxes that occur in managed and in unmanaged lands. The sum of the land use flux (IAMs) (left) and the land sink flux that occurs on managed land (DGVMs) (centre) produces an adjusted IAM CO flux that is conceptually more comparable with that of NGHGls (right). This figure may be an oversimplification as, for example, not all NGHGls include all indirect effects. DGVMs can also simulate $\mathrm{CO}_{2}$ flux due to land-use changes, but it is not considered here. See Methods for the details.

(1) the anthropogenic flux, which differs in whether or not it includes the indirect impact of human-induced environmental changes (Fig. 2a), and (2) the 'managed' area, especially for forest land (Fig. 3a).

To make the global model results and NGHGIs comparable, one can, in principle, either adapt the country model approach to the global model approach, or vice versa. Changing the country approach, which is based on several UNFCCC decisions and well-established IPCC guidelines (Supplementary Section 2), is impractical in the short term. Therefore, we explore how global models' output could be pragmatically adjusted to facilitate a like-with-like comparison. Specifically, we propose ways to reconcile different methods to estimate the 'anthropogenic' flux (Fig. 2b) and 'managed forest' (Fig. 3b-g) between global models and NGHGIs. We subsequently illustrated how these solutions can be implemented concomitantly (Fig. 4), show the impact (Fig. 5) and discuss the implications (Fig. 6).

\section{Inconsistencies in estimating the anthropogenic flux}

Conceptually, land fluxes can be differentiated ${ }^{26}$ between those due to 'direct human-induced effects' (land use and land-use change, which includes harvest and regrowth), those due to indirect human-induced effects' (that is, human-induced environmental change, which includes $\mathrm{CO}_{2}$ concentration, temperature, precipitation and nitrogen deposition feedbacks) and those due to 'natural effects' (which includes climate variability and a background natural disturbance regime, whose contribution is assumed to even out over time). Direct effects occur only in managed lands, whereas indirect and natural effects occur in both managed and unmanaged lands ${ }^{26}$.

The approach used by countries to estimate anthropogenic GHG fluxes follows the IPCC Guidelines ${ }^{25,27}$. As most NGHGIs are fully or partly based on direct observations (for example, national forest inventories), which cannot separate the direct human-induced effects from the indirect as well as natural effects ${ }^{26}$, the IPCC Guidelines adopted all GHG fluxes on managed land as a pragmatic proxy to estimate anthropogenic land GHG fluxes ${ }^{25,27}$ (Supplementary Section 2). GHG fluxes from unmanaged land are not considered anthropogenic and thus are not reported in NGHGIs. However, the degree to which direct and indirect effects are included in NGHGIs depends on the estimation method used, of which the complexity varies among countries. An earlier study ${ }^{15}$ concluded that the estimated NGHGI flux from managed forests includes the impact of all direct effects and, in most cases, indirect and natural effects (Fig. 2a, right column (Methods)).

Different types of global models are used to quantify different land $\mathrm{CO}_{2}$ fluxes. DGVMs include a process description of 
a

\begin{tabular}{|l|l|}
\hline & Forest area considered managed \\
\hline IAMs & Area of forest producing commercial wood supply for timber or energy \\
\hline NGHGIs & $\begin{array}{l}\text { Managed land is where human interventions and practices have been applied to perform production, ecological or } \\
\text { social functions (according to IPCC guidelines }\end{array}$ \\
with thresholds used in the NGHGI
\end{tabular}
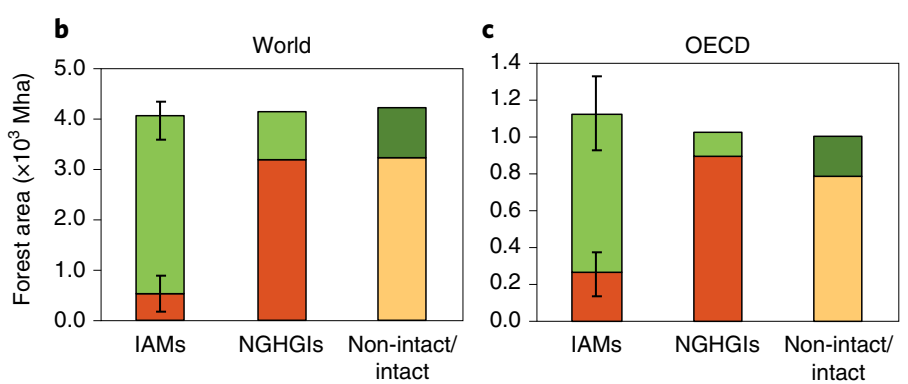

d REF

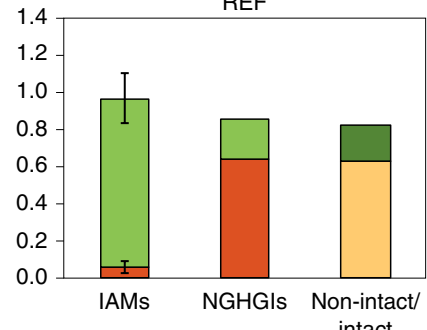

$\square$ Unmanaged

$\square$ Managed

$\square$ Intact
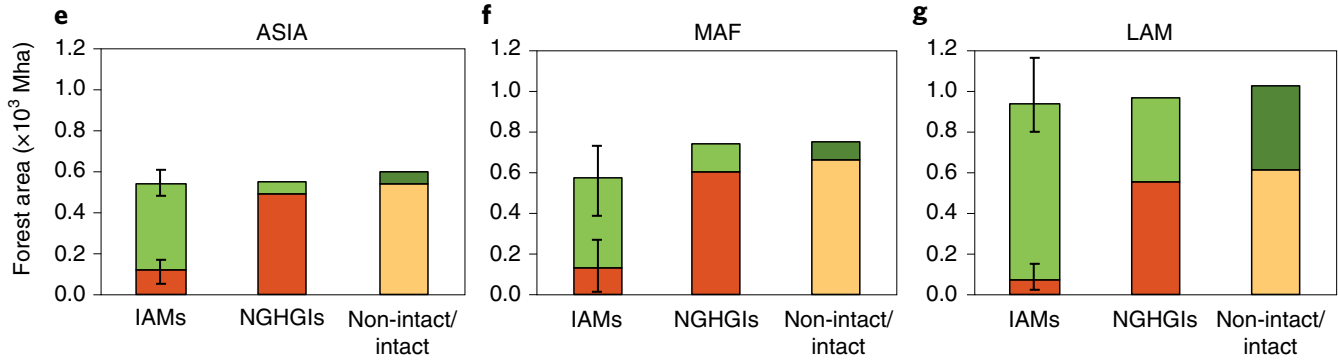

$\square$ Non-intact

h

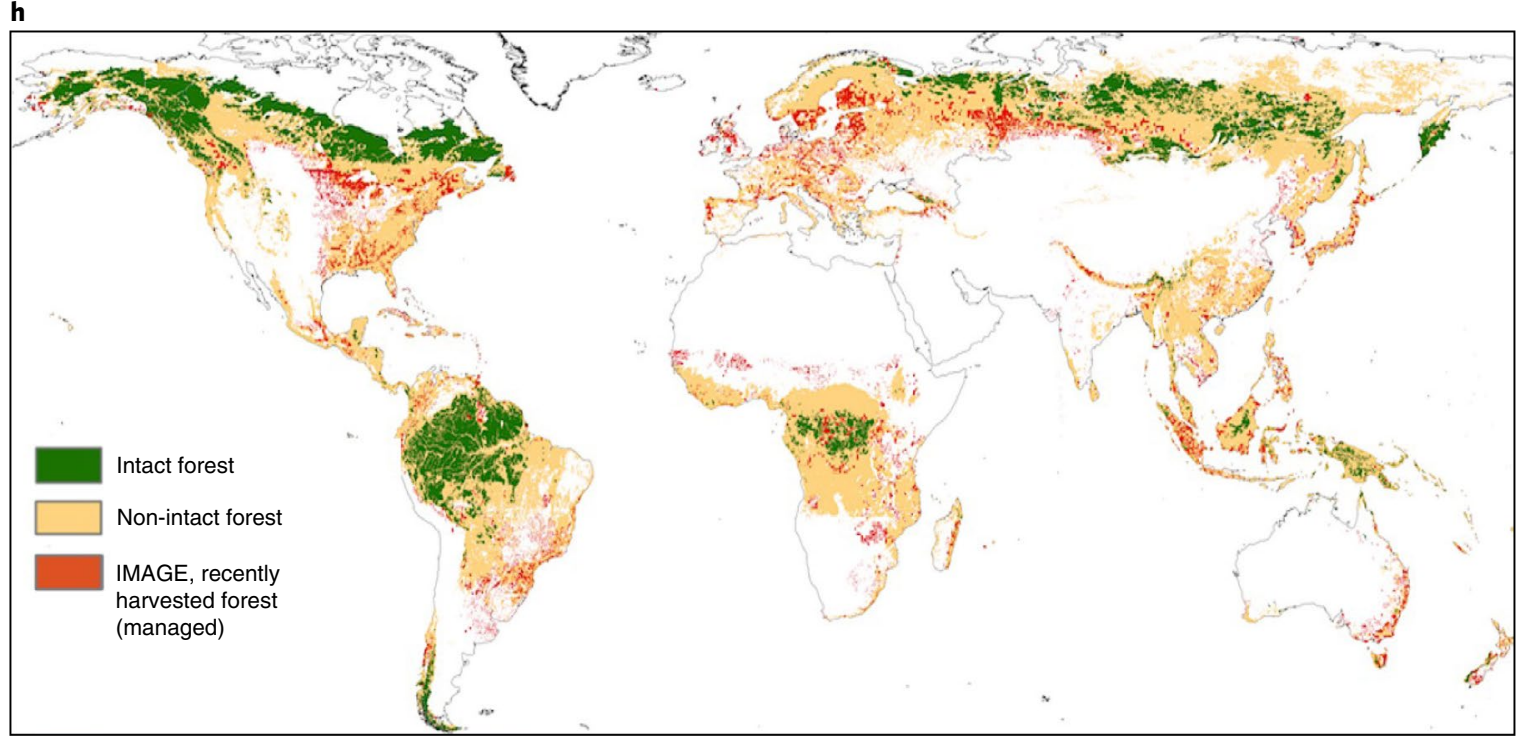

Fig. 3 | Inconsistencies between IAMs and NGHGIs in the forest areas that are considered managed, and proposed solution for their reconciliation. a, Forest area considered managed by IAMs and NGHGIs. b-g, Areas of managed and unmanaged forest in 2010, from IAMs (average of five models with minimummaximum range) and from NGHGIs, and area of intact forest in 2013 (ref. ${ }^{28}$ ) and non-intact forest (total forest area from Hansen et al. ${ }^{52}$ minus intact forest area), for the world (b) and the following regions: Developed Countries (c, OECD 90 countries (OECD, Organisation for Economic Co-operation and Development) and new EU member states and candidates), Reforming Economies of Eastern Europe and the Former Soviet Union (d, REF, excluding EU member states), Asia (e, ASIA, Asian countries with the exception of the Middle East, Japan and Former Soviet Union states), Latin America and Caribbean (LAM), and Middle East and Africa (f, MAF) and Latin America and the Caribbean ( $\mathbf{g}$, LAM). Given the good match between non-intact forest area and NGHGls' managed area (which is not available on maps), this study uses the non-intact forest area as a proxy to separate spatially the Land Sink (from DGVMs, due to indirect effects (Fig. 2b)) into fluxes that occur in managed and unmanaged areas. At the global level, NGHGI data on total and unmanaged forest area match well with the FAO-FRA 2020 (ref. $\left.{ }^{50}\right)$ data on total forest $\left(\sim 4 \times 10^{9}\right.$ ha) and primary forest $\left(\sim 1 \times 10^{9}\right.$ ha), respectively. $\mathbf{h}$, Illustrative map of intact forests, non-intact forests ${ }^{28}$ and a recently harvested area from IMAGE for the year 2010. Deforested areas are not included in any of the panels. See Methods for details.

land-related carbon fluxes, and therefore also capture the natural response of land to human-induced environmental change (indirect effects). IAMs focus on the anthropogenic land $\mathrm{CO}_{2}$ fluxes, typically including only the direct effects (land use, land-use change, harvest and regrowth, Fig. 2a, left) on land that is identified as managed in the model (Methods). Some IAMs are linked to a DGVM and use 


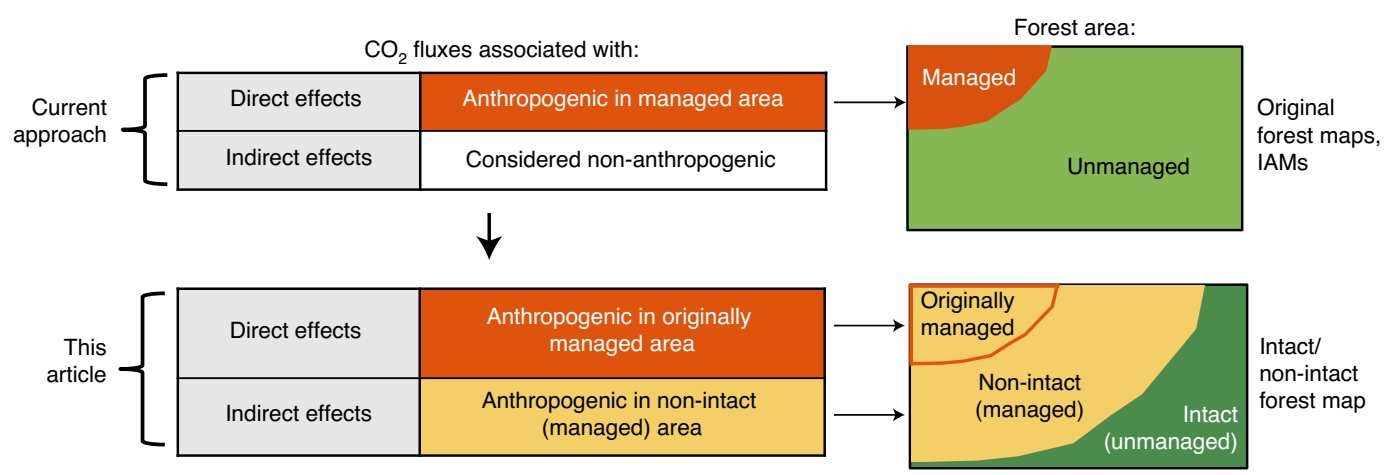

Fig. 4 | Implementation of the proposed solutions to reconcile the inconsistencies between IAMs and NGHGIs in the 'anthropogenic' forest $\mathrm{CO}_{2}$ flux. Currently (upper figures), most IAMs consider anthropogenic only the $\mathrm{CO}_{2}$ fluxes associated with direct effects (Fig. 2a, left) on a small fraction of the total forest area (managed area in the original IAMs' map (Fig. 3b)), and indirect effects on either managed or unmanaged area are not considered anthropogenic (right). In this article (lower figures), we address the inconsistencies between IAMs and NGHGIs on direct versus indirect effects (Fig. 2) and on the extent of managed forest area (Fig. 3) by adding the $\mathrm{CO}_{2}$ fluxes due to indirect effects (estimated by DGVMs (Fig. 2b)) in non-intact forest area (used as proxy of managed forest area in NGHGIs (Fig. 3b)) to the original IAMs' anthropogenic land flux. The resulting adjusted IAM results are expected to be more comparable with those of NGHGIs. In this study, the indirect effects are estimated with IMAGE/LPJmL, whose original forest map for the year 2010 is reclassified according to the intact/non-intact forest map (Fig. 3c) without changing the other land uses (for example, agriculture and urban). See Supplementary Sections 3 and 4 for details.

this (or a similar) linkage to evaluate the consequences of future land-use scenarios.

Here we propose (1) to disaggregate the land sink due to indirect effects from DGVMs into fluxes that occur in managed and unmanaged lands, and then (2) to sum the fluxes from direct effects reported by IAMs with the fluxes from indirect effects estimated by DGVMs on managed land, to obtain adjusted estimates more comparable with those of NGHGIs (Fig. 2b).

\section{Inconsistencies in managed forest area}

The NGHGIs cover all managed land-forest land, cropland, grassland, wetlands, settlements and other land. Although the relative importance of each land use varies between countries, fluxes from forest and deforestation typically comprise the vast majority of $\mathrm{CO}_{2}$ fluxes in NGHGIs (Supplementary Section 2). Furthermore, as indirect effects on non-forest lands are small compared with the effects in forest land (Methods), we concentrate only on managed forest here, because this is where most of the conceptual inconsistency occurs between IAMs and NGHGIs. The IAMs typically consider managed forests to be those forest areas that contribute to commercial wood supply (Fig. 3a). In contrast, the IPCC Guidelines ${ }^{2.5}$ used by countries define managed forest as areas 'where human interventions and practices have been applied to perform production, ecological or social functions. Country definitions are therefore flexible, must be applied consistently over time and are typically much broader than the one used by IAMs. For example, managed forest in NGHGIs includes all kinds of silvicultural activities (clear-cutting, thinnings and so on) and may include parks and protection forests, whereas IAMs include only those areas that are planted (afforestation) or subject to a (recent) wood harvest needed to fulfil timber demand, given rotation cycles and carbon densities (Methods).

A consequence of these different approaches is that the area considered managed forest by countries-about three billion hectares globally-is much bigger than that used in IAMs, despite the total forest areas (that is, managed and unmanaged combined) being similar (Fig. 3b-g). When country data for unmanaged and managed forest area are compared with the areas of 'intact forest' ${ }^{28}$ that is, forest areas characterized by no remotely detected signs of human activity (Methods) - and 'non-intact forest', respectively, a good match emerges (third column in Fig. 3b-g), both at global and regional levels. As only a few NGHGIs provide maps of their managed forests that can be used by IAMs, our method uses the non-intact forest map as a proxy for managed forests in NGHGIs. This map can then be used to spatially separate the land sink from DGVMs (Fig. 2b) into fluxes that occur in managed and unmanaged lands.

\section{Way forward to reconcile the inconsistencies}

To reconcile land-use $\mathrm{CO}_{2}$ estimates from IAMs and NGHGIs, we added fluxes estimated by DGVMs (indirect effects) in non-intact forest areas to the original IAMs' anthropogenic land fluxes (direct effects). This approach (Fig. 4) assumes that the IAMs' original flux captures the impact of the more intensive management activities (direct effects) that occur on a subset of the NGHGIs' managed area, whereas the DGVMs' flux captures the indirect effects on all the NGHGIs' managed area (Methods).

In this study, we estimated the sink due to indirect effects in the non-intact forest area with LPJmL runs associated with IMAGE (Methods and Supplementary Section 4). Given the large uncertainty of the future forest $\sin ^{29,30}$, we tested the representativeness of our results, and concluded that the forest sink estimated by LPJmL is reasonably representative of the available data in the literature (Supplementary Section 5).

\section{A consistent comparison}

In our proposed method, we first estimate the $\mathrm{CO}_{2}$ sink associated with indirect effects in non-intact forests (see Fig. $5 \mathrm{a}-\mathrm{c}$ for a selection of Shared Socio-economic Pathway 2 (SSP2) scenarios). This sink represents around $70 \%$ of the total forest sink and $50 \%$ of the total land sink in the period 2005-2050. It decreases over time in the stringent mitigation scenarios (SSP2-1.9 and SSP2-2.6), whereas it is relatively stable in a weak mitigation scenario, such as SSP2-6.0, mainly because of different $\mathrm{CO}_{2}$ concentrations and the resulting $\mathrm{CO}_{2}$ fertilization effects.

Comparing the original IAM results with the country LULUCF estimates of NGHGIs and the NDCs reveals a wide discrepancy (Fig. 5d-f). This discrepancy is largely resolved when the original IAM results are combined with the indirect human-induced sink from non-intact forests (Fig. $5 \mathrm{~g}-\mathrm{i}$ ).

For the historical period (2005-2015), the proposed adjustment reconciles IAM results with NGHGI estimates (Fig. 5j) at the global 

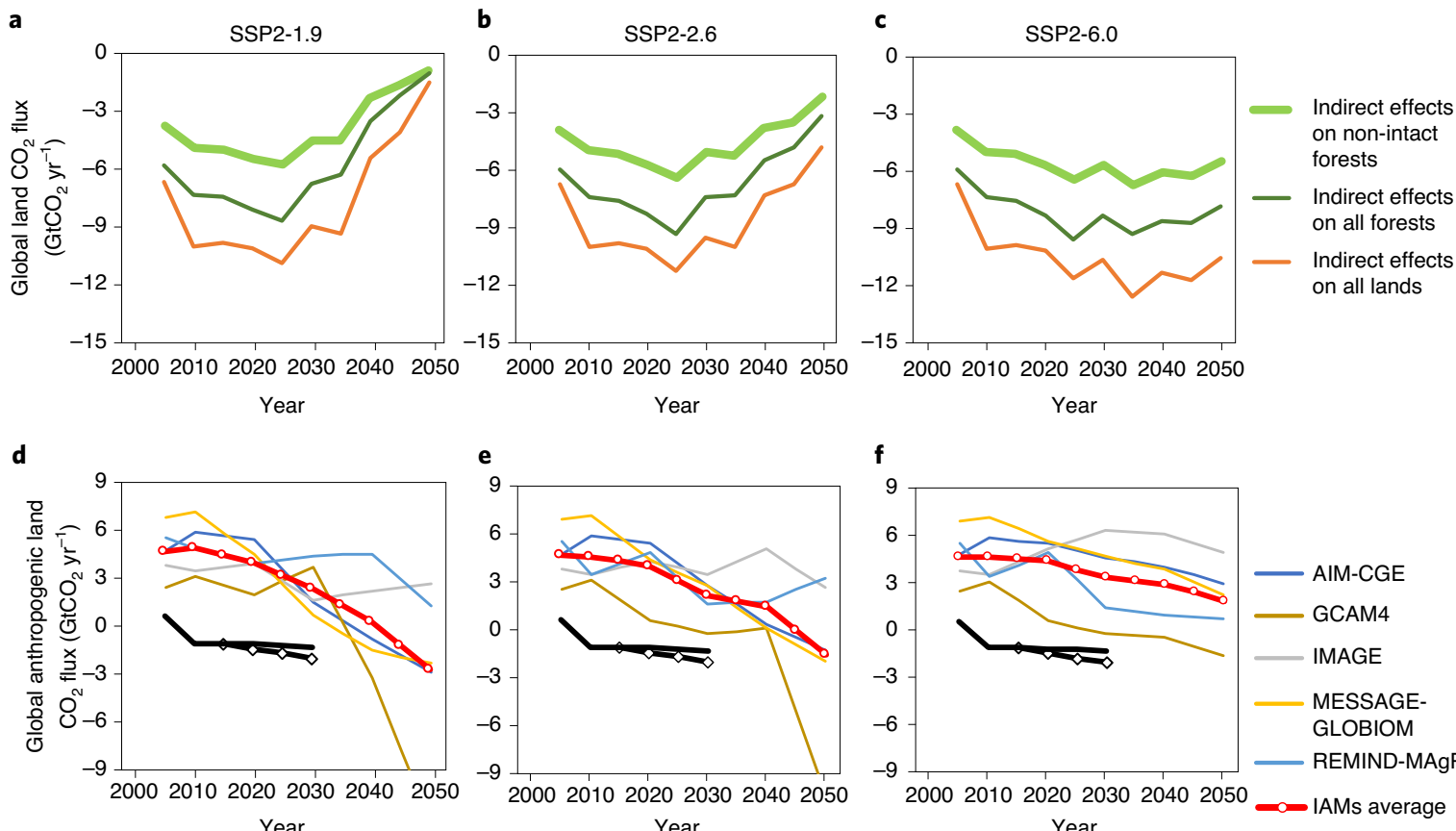

f
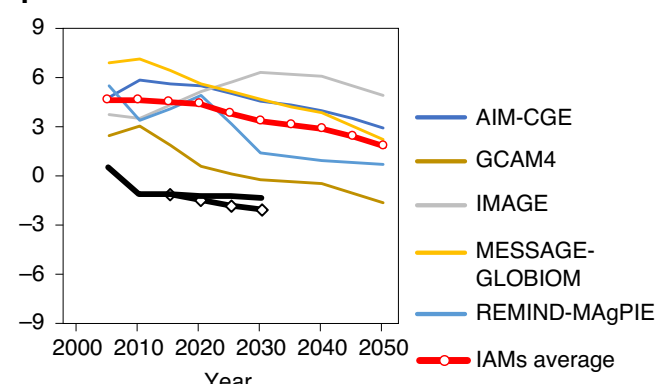

Year
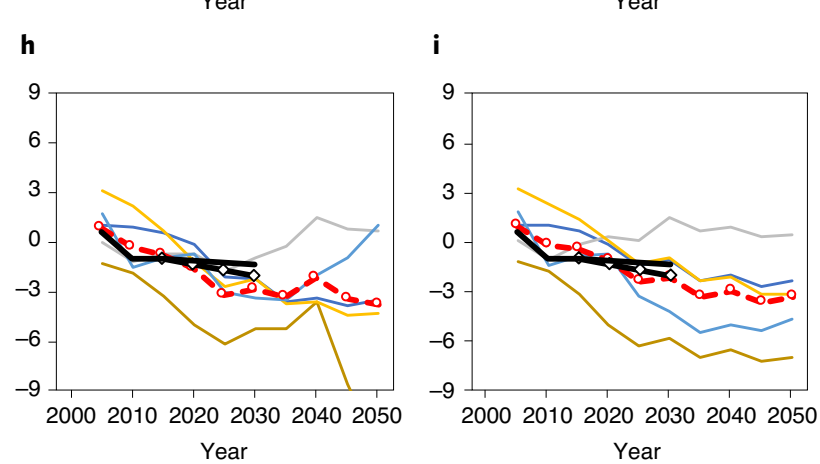
$\longrightarrow$ IAMs average
$-\infty$ IAMs average adjusted (NGHGI

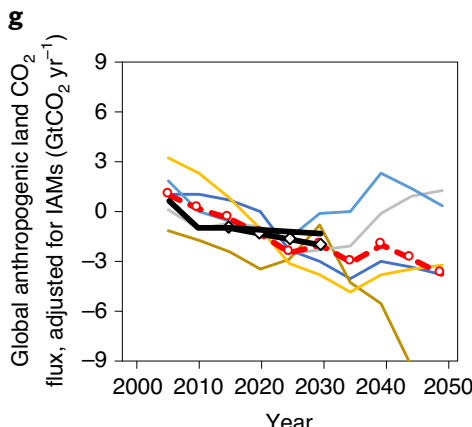
comparable)

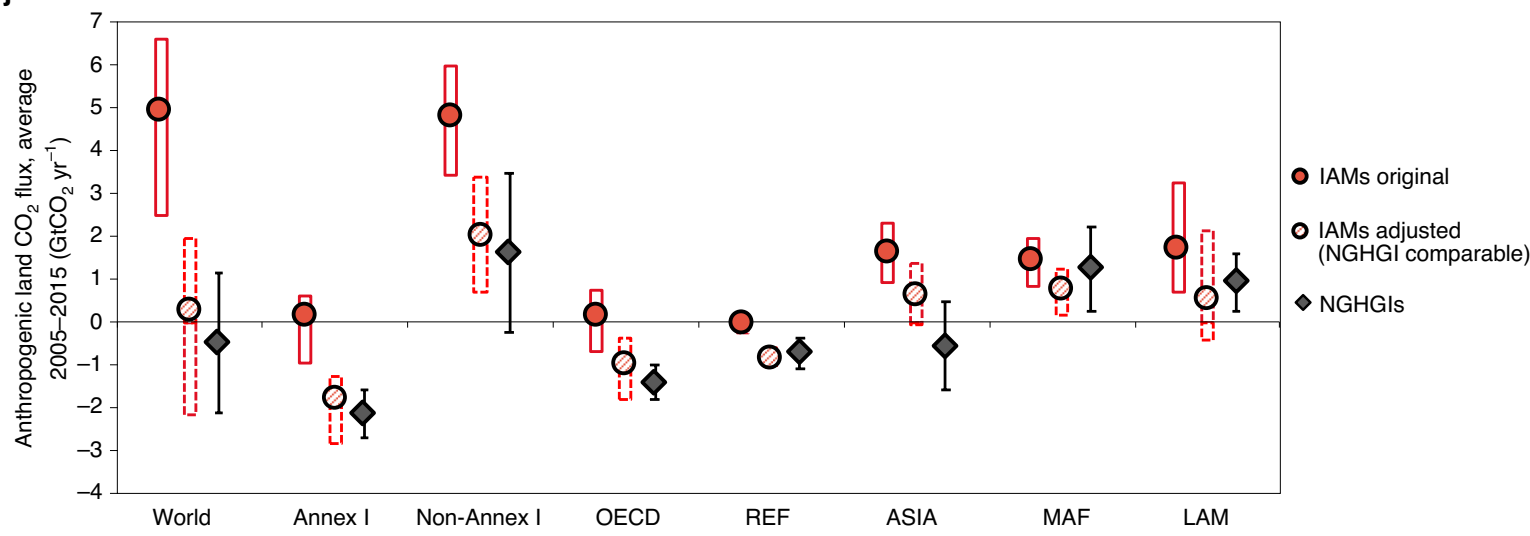

Fig. 5 | Adjustment of the IAMs' anthropogenic land $\mathrm{CO}_{2}$ fluxes to derive $\mathrm{NGHGI-comparable} \mathrm{estimates.} \mathrm{a-c,} \mathrm{Global} \mathrm{land} \mathrm{CO}_{2}$ fluxes due to indirect and natural effects from IMAGE/LPJmL for SSP2-1.9 (a), SSP2-2.6 (b) and SSP2-6.0 (c) scenarios in the period 2005-2050. d-i, Global anthropogenic land $\mathrm{CO}_{2}$ fluxes, which include the original IAM results (d-f), adjusted IAM results (NGHGI comparable (g-i)), NGHGls, and unconditional and conditional NDCs for 2030 for SSP2-1.9 (d,g), SSP2-2.6 (e,h) and SSP2-6.0 (f,i). The adjustment of IAM results ( $\mathbf{g}-\mathbf{i})$ is done by adding the indirect human-induced sink of the non-intact forests (thick green line in a) to the original IAM results (d-f). j. Anthropogenic land $\mathrm{CO}_{2}$ fluxes in the period 2005-2015, comparing the original and the adjusted IAM results (minimum-maximum range among models) to the NGHGIs ( $\pm 95 \%$ confidence interval), at the global level, for Annex I countries, non-Annex I countries and for the following regions: OECD 90 and EU, REF, ASIA, MAF and LAM. IAM data are from the SSP database. NDC data (from Grassi et al. ${ }^{3}$ ) are illustrative and do not aim to assess the future emission gap in the land sector. See Methods for details.

level, for Annex I countries (advanced economies with annual GHG reporting commitments under the UNFCCC) and for non-Annex I countries (countries with less-stringent reporting commitments).
The match between IAMs and NGHGIs improved in all the regions examined (Fig. 5 j). This pattern is also largely confirmed at the level of large countries (Supplementary Section 6), with almost full rec- 
onciliation of the estimates in European Union (EU), Russia, United States, Brazil and Indonesia, but not fully in Canada and China. This indicates that the gap between IAMs and NGHGIs is mostly a matter of the different areas considered and a different allocation of fluxes (Extended Data Fig. 1 and Supplementary Section 7). Our scenario-specific results can be directly used by other studies at the global and regional levels (Supplementary Section 8), but additional analyses would be required for specific countries.

Our approach should not be seen as the only or the final method available to reconcile estimates between IAMs and NGHGI at the country level, but rather as a pragmatic short-term fix to ensure comparability between global models and the collective country efforts during the Global Stocktake, which is essential for the implementation of the Paris Agreement. Many aspects of our method are expected to improve in the future. First, updated projections on the forest sink with a model ensemble would allow for further evaluation of the uncertainty of this sink and provide more confidence when using our approach in policy contexts. Second, the method relies on information that is appropriate at the global level, but not necessarily fully valid at the country level, such as that the non-intact forest map is a proxy of managed forest, and assumes that the NGHGI fully captures the recent indirect effects. More country-specific information, such as maps of managed forest and the extent to which indirect effects are included in the NGHGI, would help the implementation of our approach at country level. Third, the effective reconciliation between NGHGIs and IAMs shown in Fig. 5 may hide underlying uncertainties and inaccuracies through other compensating factors, such as incomplete representations of land-use processes, the absence of nitrogen fertilization and forest age-structure dynamics in IAMs, and inaccurate and/or incomplete NGHGIs.

In the medium term, countries should improve the accuracy, completeness and transparency of their NGHGIs-whenever possible also including estimates with and without the impact of indirect effects-and the clarity of the LULUCF's role within their climate targets, which currently is often ambiguous ${ }^{31}$. In parallel, IAMs (and, in general, global models) should progressively improve the representation of forest management beyond land-use changes ${ }^{32,33}$ and age-structure dynamics ${ }^{19}$. In this context, evidence from Earth Observation will play a key role both in supporting the countries' reporting and verification needs under the Paris Agreement ${ }^{34,35}$ and as a benchmark against which the land sink from global models might be evaluated ${ }^{2,36}$. Improvements on both sides (countries and global models) will raise confidence in land $\mathrm{CO}_{2}$ fluxes and support the implementation of our approach to assess collective progress.

\section{Implications for comparing targets with mitigation pathways}

The proposed approach to make the IAMs' output more comparable with that of the NGHGIs does not imply changes in the understanding of the global carbon fluxes, but simply imposes a reallocation of part of the land sink (Fig. $6 \mathrm{a}-\mathrm{d}$, for SSP2-2.6). This is done by adjusting downward the original total anthropogenic net $\mathrm{CO}_{2}$ emissions estimated by IAMs by the indirect $\mathrm{CO}_{2}$ uptake on non-intact forests (dashed black line in Fig. 6b). To avoid double counting, the natural net sink in the IAM pathways needs to be reduced (that is, adjusted upward, dashed green line in Fig. 6d) to compensate for the reallocation of the indirect $\mathrm{CO}_{2}$ sink to the anthropogenic net emissions, and thus the total net flux of $\mathrm{CO}_{2}$ to the atmosphere remains unaltered (red lines in Fig. $6 \mathrm{c}, \mathrm{d}$ ). That is, we shift a portion of the IAMs' net flux of $\mathrm{CO}_{2}$ from the natural sink to the anthropogenic component, to achieve comparability with the NGHGIs.

The implications when comparing climate targets with global mitigation pathways are illustrated in Fig. $6 \mathrm{e}-\mathrm{j}$. Our solution focuses on LULUCF, where the mismatch exists (Fig. 6e); by adding the indirect effects from non-intact forests (Fig. 6f), we adjusted the original IAMs pathways to derive NGHGI-comparable pathways for LULUCF (Fig. $6 \mathrm{~g}$ ). These changes do not affect the non-LULUCF emissions (Fig. 6h). However, the sum of LULUCF and non-LULUCF emissions ('economy-wide' emissions) then obviously also changes, and NGHGI-compatible mitigation pathways for economy-wide emissions are lower than the original ones (Fig. 6i).

Our approach does not imply modifications of the original decarbonization pathways. This is illustrated by the absence of change in the models' estimates of emissions from fossil fuels and land use in the adjustment from Fig. 6a to Fig. 6b. It simply ensures that an appropriate like-with-like comparison is made. If country climate targets using the NGHGI approach (thus, with a larger forest sink than that of IAMs) are used together with IAM pathways to assess collective climate progress, adjustments have to be made. The same reasoning applies to the remaining GHG budget (that is, the allowable emissions until net-zero GHG emissions consistent with a certain climate target). For example, for SSP2-1.9 and SSP2-2.6 (which represent pathways that keep warming to 1.5 and $2{ }^{\circ} \mathrm{C}$, respectively), the NGHGI-comparable remaining GHG budget is $120-192 \mathrm{GtCO}_{2}$ lower than the original remaining GHG budget (Fig. 6j). In the absence of these adjustments, collective progress would appear to be more on-track than it actually is.

Overall, there is no change in scientific understanding of the mitigation effort needed. However, for countries that did not account for the mismatches above when setting their targets, which include net-zero targets, correcting for this (that is, using NGHGI-comparable pathways as benchmark) will result in a perceived increase of the required mitigation effort. These implications should be urgently and clearly communicated.

The assessment of the global 2030 'emission gap' between aggregated country NDCs and specific target mitigation pathways-as published annually by the United Nations Environment Programme ${ }^{37}$-is only affected to a limited degree. This is because some estimates of global land-use emissions used in this assessment already use the same land-use approach as that of the IAM mitigation pathways ${ }^{38,39}$, or because historical data of global NDC estimates is harmonized to the historical data of global mitigation pathways (for example, Rogelj et $\mathrm{al} .{ }^{40}$ ). The latter procedure, however, is agnostic to the reasons for the observed mismatch, and often uses a constant offset ${ }^{41}$. The adjustment proposed in this article allows us to resolve this mismatch by drawing on an understanding of the underlying reasons, and thus provides a more informed and accurate basis for the estimation of the emission gap.

The inclusion of indirect effects in climate targets may raise questions of equity when countries with different levels of indirect forest sink are compared with each other or against IAMs. In both cases, equity may be enhanced when countries transparently identify the direct and indirect components in climate targets, and factor out indirect effects as appropriate. If this is not possible or practical, our approach provides a pragmatic option to exclude the impact of indirect effects when a country's climate efforts is assessed against IAM pathways (that is, the impact of indirect effects in climate targets would be counterbalanced by a similar impact in the adjusted IAM pathways). This does not suggest that indirect effects should or should not be included in climate targets, but simply facilitates a like-with-like (and thus scientifically more accurate) comparison of different country climate targets against IAM pathways, irrespective of their level of indirect forest sink.

The future evolution of the forest sink is very uncertain. Depending on the scenario, the uncertain magnitude of the $\mathrm{CO}_{2}$ fertilization effect on forest growth ${ }^{42,43}$, uncertain spatial and temporal patterns of climate change and the possibility of tipping points, the global forest sink may continue at current levels, weaken ${ }^{44}$ or even turn into a carbon source. Nevertheless, the proposed adjustment does not bring additional uncertainty into the NGHGI-comparable 

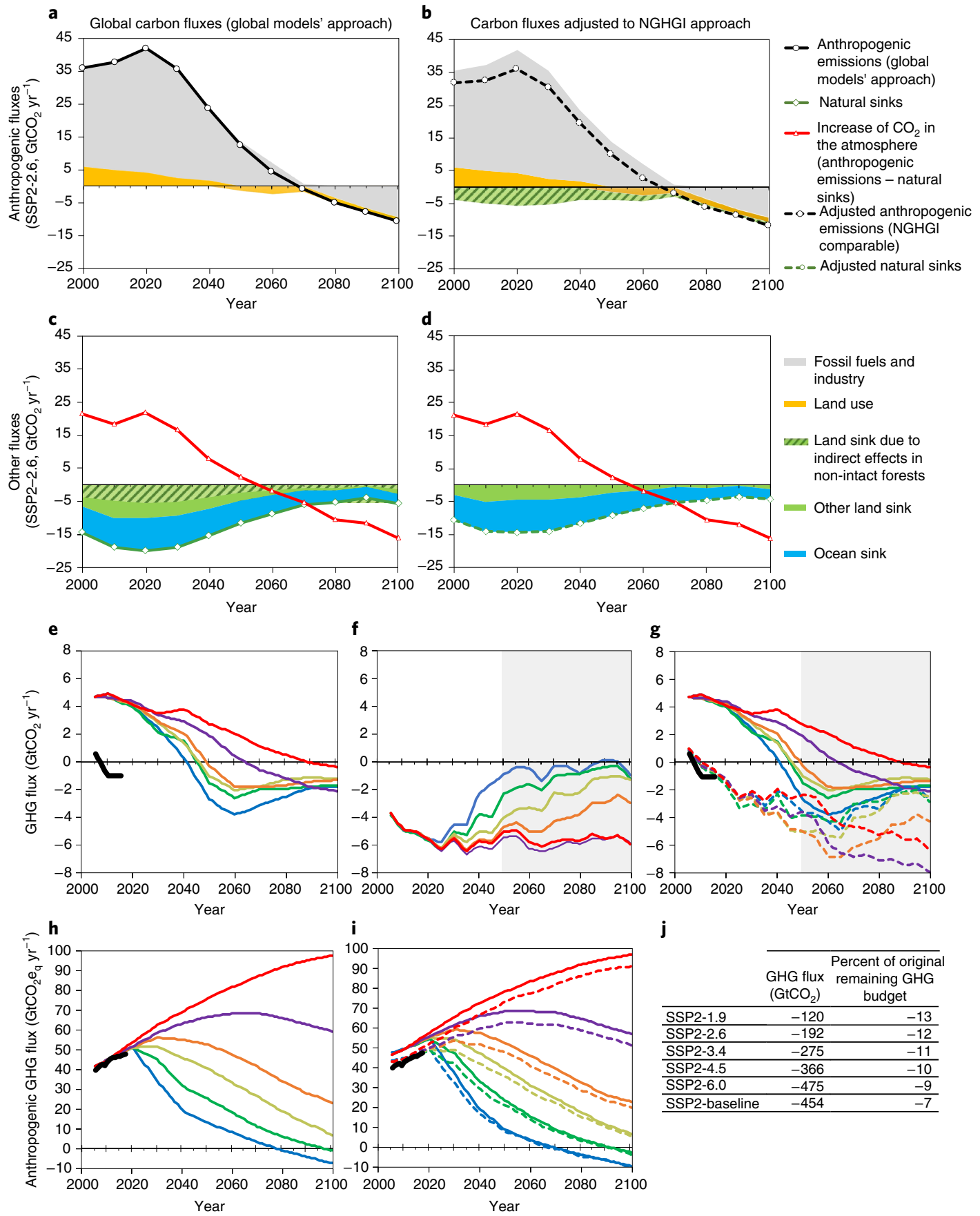

i

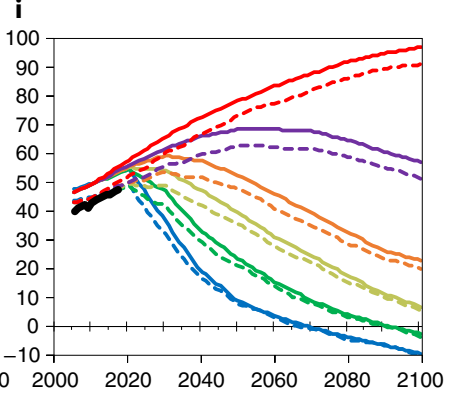

j

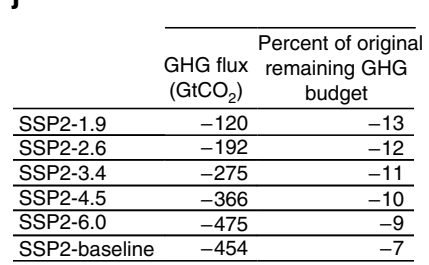

Fig. 6 I Impact of adjusting the IAMs' land $\mathrm{CO}_{2}$ fluxes to the NGHGI approach on global $\mathrm{CO}_{2}$ fluxes and the GHG mitigation pathways. a-d, Global carbon fluxes, with anthropogenic ( $\mathbf{a}, \mathbf{b}$, average of five IAMs for scenario SSP2-2.6) and other $\mathrm{CO}_{2}$ fluxes (c,d, which include natural and atmospheric sinks), according to the global models' approach $(\mathbf{a}, \mathbf{c})$ and adjusted to the NGHGI approach $(\mathbf{b}, \mathbf{d})$. This adjustment reallocates part of the land sinks considered natural by global models (due to indirect human-induced effects on non-intact forests, dashed green area in c) to the anthropogenic component (b). This improves the comparability with $\mathrm{NGHGIs,} \mathrm{but} \mathrm{does} \mathrm{not} \mathrm{change} \mathrm{the} \mathrm{CO}_{2}$ expected to remain in the atmosphere (red lines in $\mathbf{c}$ and $\mathbf{d}$ ) because changes in natural and anthropogenic land fluxes compensate. Grey areas in $\mathbf{a}$ and $\mathbf{b}$ can become negative as they can include bioenergy with carbon capture and storage. $\mathbf{e - g}$, Global $\mathrm{CO}_{2}$ fluxes from SSP2 scenarios: original IAM mitigation pathways and NGHGIs for LULUCF (e), indirect effects from non-intact forests $(\mathbf{f})$ and combination of panels $\mathbf{e}$ and $\mathbf{f}$ to obtain NGHGI-comparable anthropogenic LULUCF pathways (g, original IAM results adjusted to the $\mathrm{NGHGI}$ approach). The indirect effects in $\mathbf{f}$ decline over time with increasing mitigation ambition, mainly because of the weaker $\mathrm{CO}_{2}$ fertilization effect, and become more uncertain after 2050 (grey shading in $\mathbf{f}$ and $\mathbf{g}$ ). h,i, Global anthropogenic GHG emissions without LULUCF (h, with no adjustment needed) and combination of $\mathbf{g}$ and $\mathbf{h}$ to obtain NGHGI-comparable pathways for global GHG emissions with LULUCF (i). NGHGI data are from PRIMAP HISTCR 53 for non-LULUCF and from this study for LULUCF. j, Cumulated adjustment of IAM fluxes from 2021 until GHG neutrality or 2100 (whatever comes first). This represents the impact of our approach on the $\mathrm{NGHGI}$-comparable remaining $\mathrm{GHG}_{\text {budget }}$ (as $\mathrm{GtCO}_{2}$ or $\%$ ) relative to the original budget. See Supplementary Section 8 for regional adjustments and a version of $\mathbf{h}-\mathbf{j}$ that covers $\mathrm{CO}_{2}$ only. 
pathways. Currently, all these uncertainties on the future carbon sink are taken into account via the use of simple climate models or emulators, such as MAGICC ${ }^{45}$ used in IAMs to evaluate whether a certain mitigation pathway is consistent with a specified climate target. The behaviour of the more complex carbon cycle models that contribute to the C4MIP project ${ }^{46}$ is represented by these emulators ${ }^{45}$. The uncertainty of the future forest sink is therefore always included, independently of whether these flows are labelled as anthropogenic (as countries do) or natural (as global models do).

In conclusion, the current $5.5 \mathrm{GtCO}_{2} \mathrm{yr}^{-1}$ mismatch between IAM outputs and NGHGIs on land-related GHG fluxes means that countries cannot use the original IAM pathways as a benchmark for their collective economy-wide climate action (including LULUCF). This gap is mostly caused by differences in how the anthropogenic forest sink is assessed. In this article, we describe and apply a 'Rosetta stone' solution that translates the IAM results into the country approach and reconciles the mismatch at global and regional levels. Our scenario-specific adjustments, which can be used in other studies and refined with improved estimates of the future forest sink, offer NGHGI-comparable land-use pathways. Our solution does not change the original decarbonization pathways, but it reduces the perceived amount of allowable economy-wide cumulative net emissions for a given warming limit, relative to the original IAM pathways and related IPCC publications. Although further work is required to develop country-specific adjustments, countries that had previously used an incomparable benchmark may eventually need to update their target. The NGHGI-comparable emission pathways presented here, and the associated impact on the remaining GHG budget perceived by countries, provide essential information for the IPCC Sixth Assessment Report and the Global Stocktake and will enable a more accurate assessment of the adequacy of countries' mitigation pledges under the Paris Agreement.

\section{Online content}

Any methods, additional references, Nature Research reporting summaries, source data, extended data, supplementary information, acknowledgements, peer review information; details of author contributions and competing interests; and statements of data and code availability are available at https://doi.org/10.1038/ s41558-021-01033-6.

Received: 11 May 2020; Accepted: 26 March 2021; Published online: 26 April 2021

\section{References}

1. IPCC: Summary for Policymakers. In Special Report on Climate Change and Land (eds Shukla, P. R. et al.) (WMO, 2019).

2. Friedlingstein, P., Sullivan, M. O., Jones, M. W., Andrew, R. \& Hauck, J. Global carbon budget 2020. Earth Syst. Sci. Data 12, 3269-3340 (2020).

3. Grassi, G. et al. The key role of forests in meeting climate targets requires science for credible mitigation. Nat. Clim. Change 7, 220-226 (2017).

4. Griscom, B. W. et al. Natural climate solutions. Proc. Natl Acad. Sci. USA 114, 11645-11650 (2017)

5. Roe, S. et al. Contribution of the land sector to a $1.5^{\circ} \mathrm{C}$ world. Nat. Clim. Change 9, 817-828 (2019).

6. Fuglestvedt, J. et al. Implications of possible interpretations of 'greenhouse gas balance' in the Paris Agreement. Philos. Trans. R. Soc. A 376, 20160445 (2018)

7. Adoption of the Paris Agreement FCCC/CP/2015/L.9/Rev.1 (UNFCC, 2015); http://unfccc.int/resource/docs/2015/cop21/eng/109r01.pdf

8. Clarke L. et al. in Climate Change 2014: Mitigation of Climate Change (eds Edenhofer, O. et al) Ch. 6 (Cambridge Univ. Press).

9. Riahi, K. et al. The Shared Socioeconomic Pathways and their energy, land use, and greenhouse gas emissions implications: an overview. Glob. Environ. Change 42, 153-168 (2017).

10. Rogelj J. et al. in IPCC Special Report on Global Warming of $1.5^{\circ} \mathrm{C}$ (eds Masson-Delmotte, V. et al.) Ch 2 (WMO, 2018).

11. Smith, P. et al. in IPCC Climate Change 2014: Mitigation of Climate Change (eds Edenhofer, O. et al.) Ch. 11 (Cambridge Univ. Press, 2014).
12. IPCC: Summary for Policymakers. In Special Report on Global Warming of $1.5^{\circ} \mathrm{C}$ (WMO, 2018)

13. van Vuuren, D. P. et al. Energy, land-use and greenhouse gas emissions trajectories under a green growth paradigm. Glob. Environ. Change $\mathbf{4 2}$, 237-250 (2017).

14. Popp, A. et al. Land-use futures in the shared socio-economic pathways. Glob. Environ. Change 42, 331-345 (2017).

15. Grassi, G. et al. Reconciling global-model estimates and country reporting of anthropogenic forest $\mathrm{CO}_{2}$ sinks. Nat. Clim. Change 8, 914-920 (2018)

16. Joint SBSTA-IPCC Special Event: Special Report on Climate Change and Land (UNFCCC, 2019); https://sdg.iisd.org/events/ joint-sbsta-ipcc-special-event-special-report-on-climate-change-and-land-srccl /https://unfccc-cop25.streamworld.de/webcast/ joint-sbsta-ipcc-special-event-special-report-on-c

17. Pongratz, J., Reick, C. H., Houghton, R. A. \& House, J. I. Terminology as a key uncertainty in net land use and land cover change carbon flux estimates. Earth Syst. Dyn. 5, 177-195 (2014)

18. Kauppi, P. E. et al. Carbon benefits from forest transitions promoting biomass expansions and thickening. Glob. Change Biol. 26, 5365-5370 (2020).

19. Pugh, T. A. M. et al. Role of forest regrowth in global carbon sink dynamics. Proc. Natl Acad. Sci. USA 116, 4382-4387 (2019).

20. Fujimori, S. et al. SSP3: AIM implementation of shared socioeconomic pathways. Glob. Environ. Change 42, 268-283 (2017).

21. Calvin, K. et al. SSP4: a world of inequality. Glob. Environ. Change $\mathbf{4 2 ,}$ 284-296 (2016)

22. Fricko, O. et al. The marker quantification of the Shared Socioeconomic Pathway 2: A middle-of-the-road scenario for the 21st century. Glob. Environ. Change 42, 251-267 (2017).

23. Kriegler, E. Fossil-fueled development (SSP5): an energy and resource intensive scenario for the 21st century. Glob. Environ. Change 42, 297-315 (2017)

24. Schaphoff, S. et al. LPJmL4-a dynamic global vegetation model with managed land: Part II-model evaluation. Geosci. Model Dev. 11, 1377-1403 (2018)

25. IPCC Guidelines for National Greenhouse Gas Inventories (eds Eggleston, H. S. et al.) (Institute for Global Environmental Strategies, 2006).

26. IPCC Revisiting the Use of Managed Land as a Proxy for Estimating National Anthropogenic Emissions and Removals (eds Eggleston, S. et al.) (Institute for Global Environmental Strategies, 2010); https://www.ipcc-nggip.iges.or.jp/ public/mtdocs/pdfiles/0905_MLP_Report.pdf

27. IPCC 2019 Refinement to the 2006 IPCC Guidelines for National Greenhouse Gas Inventories (eds Calvo Buendia, E. et al.) Vol. 2 (WMO, 2019).

28. Potapov, P. et al. The last frontiers of wilderness: tracking loss of intact forest landscapes from 2000 to 2013. Sci. Adv. 3, 1-14 (2017).

29. Müller, C. et al. Drivers and patterns of land biosphere carbon balance reversal. Environ. Res. Lett. 11, 044002 (2016).

30. Tharammal, T., Bala, G., Devaraju, N. \& Nemani, R. A review of the major drivers of the terrestrial carbon uptake: model-based assessments, consensus, and uncertainties. Environ. Res. Lett. 14, 093005 (2019).

31. Fyson, C. L. \& Jeffery, M. L. Ambiguity in the land use component of mitigation contributions toward the Paris Agreement goals. Earth Future 7 , 873-891 (2019)

32. Erb, K. et al. Unexpectedly large impact of forest management and grazing on global vegetation biomass. Nature 553, 73-76 (2018).

33. Schelhaas, M. J. et al. Actual European forest management by region, tree species and owner based on 714,000 re-measured trees in national forest inventories. PLoS ONE 13, 1-23 (2018).

34. Harris, N. L. et al. Global maps of twenty-first century forest carbon fluxes. Nat. Clim. Change 11, 234-239 (2021).

35. Ceccherini, G. et al. Abrupt increase in harvested forest area over Europe after 2015. Nature 583, 72-77 (2020).

36. Houghton, R. A. et al. Terrestrial fluxes of carbon in GCP carbon budget. Glob. Change Biol. 26, 3006-3014 (2020).

37. Emissions Gap Report 2019 (United Nations Environment Programme, 2019).

38. Rogelj, J. et al. Understanding the origin of Paris Agreement emission uncertainty. Nat. Commun. 8, 15748 (2017).

39. McCollum, D. L. et al. Energy investment needs for fulfilling the Paris Agreement and achieving the Sustainable Development Goals. Nat. Energy 3, 589-599 (2018).

40. Rogelj, J., Hare, W., Chen, C. \& Meinshausen, M. Discrepancies in historical emissions point to a wider 2020 gap between $2 \mathrm{C}$ benchmarks and aggregated national mitigation pledges. Environ. Res. Lett. 6, 02400 (2011).

41. van Soest, H. L., den Elzen, M. G. J. \& van Vuuren, D. P. Net-zero emission targets for major emitting countries consistent with the Paris Agreement. Nat. Commun. 12, 2140 (2021).

42. Haverd, V. et al. Higher than expected $\mathrm{CO}_{2}$ fertilization inferred from leaf to global observations. Glob. Chang. Biol. 26, 2390-2402 (2020). 
43. Jiang, M. et al. The fate of carbon in a mature forest under carbon dioxide enrichment. Nature 580, 227-231 (2020).

44. Hubau, W. et al. Asynchronous carbon sink saturation in African and Amazonian tropical forests. Nature 579, 80-87 (2020).

45. Meinshausen, M., Raper, S. C. B. \& Wigley, T. M. L. Emulating coupled atmosphere-ocean and carbon cycle models with a simpler model, MAGICC6Part 1: Model description and calibration. Atmos. Chem. Phys. 11, 1417-1456 (2011)

46. Jones, C. D. et al. C4MIP-the Coupled Climate-Carbon Cycle Model Intercomparison Project: experimental protocol for CMIP6. Geosci. Model Dev. 9, 2853-2880 (2016)

47. Friedlingstein, P. et al. Global carbon budget 2019. Earth Syst. Sci. Data 11, 1783-1838 (2019).

48. Riahi, K., Grübler, A. \& Nakicenovic, N. Scenarios of long-term socio-economic and environmental development under climate stabilization. Technol. Forecast. Soc. Change 74, 887-935 (2007).
49. FAOSTAT Land Use Emissions (FAO, accessed 30 October 2020); http://www. fao.org/faostat/en/\#data/GF/visualize

50. Chen, Y., Feng, X. \& Fu, B. An improved global remote-sensing-based surface soil moisture (RSSSM) dataset covering 2003-2018. Earth Syst. Sci. Data 13, 1-31 (2021).

51. Erb, K.-H. et al. Bias in the attribution of forest carbon sinks. Nat. Clim. Change 3, 854-856 (2013).

52. Hansen, M. C. et al. High-resolution global maps of 21st-century forest cover change. Science 342, 850-853 (2013).

53. Gütschow, J. et al. The PRIMAP-hist national historical emissions time series. Earth Syst. Sci. Data 8, 571-603 (2016).

Publisher's note Springer Nature remains neutral with regard to jurisdictional claims in published maps and institutional affiliations.

(C) The Author(s), under exclusive licence to Springer Nature Limited 2021 


\section{Methods}

Country data submitted to UNFCCC. In this study, we use the term national greenhouse gas inventory (NGHGI) in a broad sense, which includes anthropogenic historical GHG data within any country GHG report submitted to UNFCCC. Although the Paris Agreement removes the previous distinction between Annex I and non-Annex I countries in terms of targets and reporting (retaining some flexibility in GHG reporting for developing countries), we use this distinction here because it still reflects relevant differences in historical GHG data (see below). A general description of NGHGI estimation, reporting, accounting and review under the UNFCCC is included in Supplementary Section 2.1.

The global historical (2000-2017) LULUCF country $\mathrm{CO}_{2}$ dataset used here (Fig. 1a) is an update to February 2021 of the dataset in Grassi et al. ${ }^{15}$. It includes data from all Annex I countries (for which a complete time series, 1990-2018, is available) and from most non-Annex I countries (incomplete time series, here gap filled for the period 2000-2017). To date, this dataset is the most comprehensive collection of the available country LULUCF estimates (Supplementary Section 2.2).

In principle, LULUCF includes all land uses (forest land, cropland, grassland, wetlands, settlements and other land). In practice, although almost all Annex I countries report all land uses, many non-Annex I countries report only on forest land and deforestation (that is, forest converted into other land uses). When splitting the net LULUCF flux into the three categories 'forest', 'deforestation' and 'other' (which includes peat decomposition in Indonesia), forest and deforestation represent more than $95 \%$ of the sum of absolute fluxes from the three categories in both Annex I and non-Annex I countries (Supplementary Section 2). This does not mean that other fluxes are unimportant-for example, emissions from agricultural organic soils or removals from grasslands may be relevant in some countries-but simply that at the global level their net sum is close to zero in NGHGIs. In Fig. $1 b$, 'emissions' include fluxes from deforestation and, for Indonesia, peat fires; 'removals' include fluxes from forest land and from 'other'.

In terms of gases, although the information sources used (see below) include reporting for all GHGs, in this article we consider only $\mathrm{CO}_{2}$ to allow comparability with IAM data. Exceptions are a few non-Annex I countries for which it was not possible to separate $\mathrm{CO}_{2}$ from non- $\mathrm{CO}_{2}$ emissions (mainly $\mathrm{CH}_{4}$ and $\mathrm{N}_{2} \mathrm{O}$ from forest fire). However, this contribution is assumed to be relatively small, for example, for Annex I countries, the non- $\mathrm{CO}_{2}$ emissions are around $6 \%$ of the total $\mathrm{CO}_{2}$-equivalent net LULUCF GHG flux, but for Brazil they are $10 \%$.

In terms of carbon pools, the forest biomass is always reported and typically represents the vast majority of LULUCF fluxes. Dead organic matter and mineral soils are reported by most Annex I countries and by the biggest non-Annex I countries for conversions between land uses, but these pools are often assumed to be in equilibrium for forest land that remains forest land. Emissions from organic soils and peatland are typically reported when relevant. As most of the IAMs do not include carbon stock changes in harvested wood products (HWP), country data on HWP are not included here. Based on the information reported in the NGHGIs (mostly from Annex I countries), HWP represents a global sink of about $-0.2 \mathrm{GtCO}_{2} \mathrm{yr}^{-1}$ (average 2005-2015), therefore its omissions here does not substantially affect our analysis.

The key statistics on the information sources used are illustrated in Supplementary Table 2. A summary of the most relevant historical data used in this study (area of managed forest and LULUCF $\mathrm{CO}_{2}$ emissions and removals) is presented in Supplementary Tables 3 and 4 for all Annex I and for the main non-Annex I countries, respectively.

For Annex I countries (43 countries with advanced economies and annual NGHGI reporting commitments under the UNFCCC), the 2000-2017 time series of LULUCF $\mathrm{CO}_{2}$ estimates used in this study is taken from the National Inventory Submissions ${ }^{55}$ submitted in 2020, and in most cases includes all land uses, most carbon pools (except HWPs) and $\mathrm{CO}_{2}$ emissions from fires

For non-Annex I countries (152 countries with less stringent reporting commitments to UNFCCC), the data for periodicity, accuracy, transparency and completeness of NGHGI reporting vary considerably. For this reason, where necessary, we applied filters and gap filling for the period 2000-2017.

For these countries, a priority hierarchy of data sources was established. First, only post- 2015 country submissions to UNFCCC were considered, generally prioritizing the more recent one: $\mathrm{NDCs}^{56}$ (typically submitted in 2015), National Communications ${ }^{57}$ or Biennial Update Reports ${ }^{58}$ and REDD+ submissions ${ }^{59}$ (if covering the entire country territory). This filter restricted the LULUCF $\mathrm{CO}_{2}$ data to 106 countries, which represent $98 \%$ of the forest area of all non-Annex I countries (Supplementary Table 2). This number is larger than those in similar recent analyses ${ }^{15}$, a witness to the relatively rapid improvement in the quantity (and in some case quality) of NGHGI information from non-Annex I countries. Data from non-Annex I countries includes mostly forest-related $\mathrm{CO}_{2}$ fluxes (including deforestation and fires), with only few countries that also report cropland and grassland. In a few cases, additional criteria were used to exclude data that was considered not plausible (Supplementary Table 3).

For the remaining 46 non-Annex I countries (typically small countries), either the information submitted to UNFCCC was considered old $(<2015)$ or was not available. In this case, data on forest-related $\mathrm{CO}_{2}$ fluxes were obtained based on the country reports to FAO-FRA 2015, as elaborated by Federici et al. ${ }^{60}$. To approximate what the countries will likely submit under the Global Stocktake, in this article we focus only on $\mathrm{CO}_{2}$ information directly provided by the countries to UNFCCC or elaborated based on country data reported to FAO-FRA. Non-forest GHG data reported in the FAOSTAT database ${ }^{49}$, although potentially valuable to gap fill incomplete country GHG data, are not used here because they are not directly based on country data.

Second, as many non-Annex I countries do not report a complete times series, any missing data between 2000 and 2017 was obtained by linear interpolation of the available data (if the gap was between two data) or by backward or forward extrapolation of the closest data.

Use of the managed land proxy. The vast majority of countries that submitted GHG data to UNFCCC implicitly use the 'managed land' proxy (that is, that all GHG fluxes from managed lands are anthropogenic) following either the 2003 IPCC Good Practice Guidance ${ }^{61}$ or the 2006 IPCC Guidelines ${ }^{25}$; however, only a minority explicitly report information on the implementation of this proxy ${ }^{15,62}$. Although the lack of such information is often associated with the assumption that most or all land is managed, there is a clear need for greater transparency by countries on this issue $e^{62}$.

All Annex I countries use the 2006 IPCC Guidelines ${ }^{25}$. Most of these countries consider all land as managed (many EU countries), but some countries (for example, the United States, Canada and Russia) specifically report the area of unmanaged lands (for forest land, grasslands and wetlands, without estimating the corresponding GHG fluxes, consistent with IPCC Guidelines).

The vast majority of the 106 non-Annex I countries for which GHG data submitted to UNFCCC is used in this paper implicitly use the managed land proxy $^{25,61}$. However, an explicit separation of managed and unmanaged areas is reported only in a few cases (for example, Brazil). When available, here we considered as managed forest the area of forest used to compute the GHG fluxes reported to UNFCCC. Where this information was not available, we used the area of secondary forests and plantations from the country reports to FAO-FRA 2015 (ref. ${ }^{60}$ ) as a proxy of managed forest.

Although the direct effects are, in principle, always fully included in the NGHGIs, the inclusion of indirect effects depends on the estimation methods used, which differ in approach and complexity among countries. Especially for non-Annex I countries, these methods are not always reported in a transparent way. Previous studies ${ }^{15}$ concluded that the impact of recent indirect anthropogenic effects is included in the NGHGIs of the vast majority of Annex I countries (with a few exceptions, for example, Australia, Canada and Japan) and at least in the most important non-Annex I countries (in terms of forest $\mathrm{CO}_{2}$ sinks: China, Brazil, Malaysia, Mexico and India) (Supplementary Table 1).

The values of NGHGI uncertainty in Figs. $1 \mathrm{~b}$ and $5 \mathrm{j}$ are based on information from countries' reports to UNFCCC, complemented by expert judgement (see the Supplementary Information of Grassi et al. ${ }^{3}$ ) and then aggregated at regional and global levels. Overall, the uncertainty on the net LULUCF $\mathrm{CO}_{2}$ flux is estimated to be around $35 \%$ for Annex I countries and 50\% for non-Annex I countries. Given the incomplete information on the uncertainty of NGHGIs (especially for non-Annex I countries), these values should be considered as order-of-magnitude estimates.

For the projections up to 2030, here we use the data from $\mathrm{NDCs}^{56}$ as extracted by Grassi et al. ${ }^{3}$, for both Annex I and non-Annex I countries, normalized with the here-updated data for the five-year average around 2010. Despite the considerable uncertainty in the land-use contribution to the NDCs, the trends found by Grassi et al. ${ }^{3}$ are consistent with other independent assessments (for example, Fyson and Jeffery $^{31}$ and Forsell et al. ${ }^{63}$ ). In the context of this article, these trends (as shown in Figs. 1 and 5) are illustrative and do not aim to quantify the future emissions gap in the land sector.

Other datasets. The forest-related FAO data in Fig. 1a are from FAOSTAT ${ }^{49}$. They refer to emissions and removals in biomass from forest land and deforestation, computed by Tubiello et al. ${ }^{50}$ as the change in carbon stock using data in country reports to FAO-FRA 2020. Although in these country reports the forest carbon stock values, in principle, refer to the entire forest land area reported to FAO (that is, without differentiating between primary, naturally regenerated and planted forest categories), in most cases it can be noted that the dynamics of the carbon stocks in forest land are those typical of managed forest only. Overall, although forest-related FAOSTAT estimates are not always fully comparable with NGHGIs, because of the possible differences in the pools and, in a few cases, in the area included (some NGHGIs may include less area than that in FAO-FRA 2020, but they often include non-biomass pools), the net global impact of these differences is considered to be small.

The PRIMAP-hist dataset ${ }^{53}$ (Fig. 6) combines several published datasets to create a comprehensive set of GHG emission pathways for every country and Kyoto gas, and all UNFCCC member states. In the PRIMAP-HISTCR dataset used here, country-reported data submitted to UNFCCC is prioritized over third-party data.

IAMs. All the IAM scenario data we used in this study is based on SSP2 (ref. ${ }^{22}$ ). The SSPs depict five different global futures (SSP1-SSP5) with substantially different socio-economic conditions that aim to reflect different socio-economic challenges to mitigation and adaptation ${ }^{9}$. SSP2 describes medium challenges of 
both kinds and is intended to represent a future in which development trends are not extreme in any of the dimensions, but rather follow middle-of-the-road pathways ${ }^{22}$. The SSPs can be combined with different climate policy assumptions. Here, we use the results of SSP2 combined with different end-of-century radiative forcing levels ${ }^{64}$, namely 1.9, 2.6, 3.4, 4.5, 6.0 and baseline. These scenarios were derived by five different IAMs with global coverage ${ }^{9,65}: \mathrm{AIM}^{20}, \mathrm{GCAM}^{21}$, IMAGE ${ }^{13}$, MESSAGE-GLOBIOM $^{22}$ and REMIND-MAgPIE ${ }^{23}$. The vast majority of IAM data used here were taken from the public SSP web database hosted by the International Institute for Applied System Analysis (https://tntcat.iiasa.ac.at/SspDb/dsd?Action= htmlpage\&page=welcome), with the rest directly from the modelling teams (from IMAGE and LPJmL).

All the IAMs have in common that they contain land-use modules, which differ, however, in their representation and parametrization of biogeochemical, biophysical and socio-economic processes as well as in their spatial resolution ${ }^{14}$. All the IAMs are driven by the same projections of economic growth and population, developed for the SSPs. For other characteristics of the storylines (such as yield increases, land-use change regulation and trade), the modelling teams have made their own assumptions on how to best represent the described trends of these drivers. More detailed descriptions of the individual land-use modules can be found in Supplementary Section 3 and in the Supplementary Material of Popp et al. ${ }^{14}$.

Although IAMs differ in how they calculate the area of managed forest, in principle they all base it on following elements: (1) forest product demand (mostly based on FAO statistics and then projections into the future), (2) carbon density of forests and/or timber that can be harvested per hectare increments and (3) estimates on length of rotation cycles and/or year to maturity. Consequently, the area of managed forest represents the area required to provided historic and future demand for wood products in continuous harvest rotations. The resulting area is substantially lower than both FAO's non-primary forest (secondary forest and plantations) and NGHGIs' managed area, as large forest areas are, in reality, multipurpose, not subject to clear-cuts only and have no or much longer rotation length (period from one harvest to the next) than assumed by IAMs (see Supplementary Section 7 for more details).

The emissions from IAMs in Fig. 1b are mostly from deforestation and partly from non-forest land use.

Calculation of the adjustment factors. The adjustment of the IAM results presented here (Figs. 5 and 6) uses the forest sink due to indirect effects in non-intact forests, as estimated by LPJmL in combination with IMAGE. LPJmL model 4.0 (ref. ${ }^{24}$ ) is fully coupled and an integral part of IMAGE ${ }^{66}$. In this coupling ${ }^{29}$, IMAGE provides gridded land use, climate and $\mathrm{CO}_{2}$ concentrations to LPJmL, and receives agricultural production, vegetation structure, carbon stocks and fluxes, and water fluxes, all on a spatial grid of $0.5^{\circ}$ resolution and annual time steps. The gridded precipitation and temperature in IMAGE are derived from a change in global mean temperature calculated by the internally coupled MAGICC model $^{45}$, plus a pattern scaling based on IPCC's AR5 climate model output $^{66}$. As 30-year averages are used from the climate model patterns, interannual variability is added within $\mathrm{LPJmL}^{29}$. LPJmL coupled to IMAGE accounts for forest management, following IMAGE's forest harvest and management module with three different management types and calibrated rotation cycles and harvest characteristics ${ }^{6,67}$. We derived the indirect effects by grid cell and time step via counterfactual LPJmL runs with and without climate change.

The intact forest map was produced by the Intact Forest Landscapes project ${ }^{28}$ (www.intactforest.org). Intact forest landscapes (IFLs) are defined as areas within the current forest landscape extent characterized by no remotely detected signs of human activity or habitat fragmentation and large enough to maintain all native biological diversity. Forests are defined as areas with a tree canopy cover greater than $20 \%$, as identified by the Global Forest Change dataset by Hansen et al. ${ }^{52}$, derived from Landsat imagery. In 2000 , IFLs covered globally $30 \%$ of the total forest area over 65 countries. IFLs were identified based on the absence of settlements, infrastructures (roads, railways, pipelines, power transmission lines and waterways), agriculture or timber production, and industrial activities in the past 30-70 years, which include oil and gas exploration and extraction, and peat extraction. Human activity and disturbances were identified with moderate-resolution satellite imagery and existing settlements and infrastructure maps, and used to map altered and fragmented forest areas in the forest map and consequently the remaining intact areas. IFL maps are available for the years 2000, 2013 and 2016. In this work, non-intact forest was derived by spatially subtracting IFL areas from the same global forest maps of the Global Forest Change dataset, coherent with the approach used to identify intact forest landscapes. Although non-intact forest represents a good proxy for managed forest in NGHGIs at the global level and for individual regions (Fig. 3), this is not necessarily valid for all individual countries.

To calculate the forest sink due to indirect effects in non-intact forests, the original gridded map from IMAGE/LPJmL for the year 2010 was reclassified according to the satellite-derived intact and non-intact forest map from Potapov et al. ${ }^{28}$ and Hansen et al. ${ }^{52}$ for the year 2013 (Fig. 3h), without changing the other land uses (for example, agriculture and urban). The procedure is described in detail in Supplementary Section 4. For the future, any projected change in the original
IMAGE managed forest area (due to afforestation, deforestation or new harvest in previously unmanaged forests) is taken into account and the associated $\mathrm{CO}_{2}$ flux counted as land-use flux (Supplementary Fig. 4). The differences in future forest area changes between each IAM and IMAGE were also considered (Supplementary Section 4)

In calculating the adjustment to IAMs, we considered only the impact of indirect effects in forest areas. The rationale for not considering the possible indirect effects on non-forest areas include: (1) evidence from models that most of land sink occurs on forests (Fig. 5a-c and Grassi et al. ${ }^{15}$ ), as confirmed by inventory methods (for example, Pan et al. ${ }^{68}$ ) and by the NGHGIs of Annex I countries (where the sink of non-forest land categories is very small compared to the forest sink); (2) non-forest land is scarcely reported in non-Annex I countries (for the purpose of this article, it is not meaningful to correct IAM results for something that is very partially reported by countries); (3) although most countries include most of the indirect effects on their forest $\mathrm{CO}_{2}$ estimates, it is more difficult to assess the extent to which the impact of indirect effects is captured for non-fores land (when reported by countries) and (4) although 'intact/non-intact forest' is a good proxy for 'managed/unmanaged forest', no similar reliable proxy exists for other land uses (for example, grassland).

Our approach assumes that indirect effects estimated by LPJmL are additive to the direct management effects estimated by IAMs (no double counting is expected) because none of the current IAM models and scenarios include recent and future indirect effects (Supplementary Section 3 and Popp et al. ${ }^{14}$ ).

Representativeness of the forest $\mathrm{CO}_{2}$ sink from LPJmL. Given the data requirement for this study (for example, spatially gridded data from a DGVM linked to an IAM), only LPJmL is available as a model to estimate the indirect human-induced forest sink. However, as the future forest sink is known to be very uncertain ${ }^{29,30}$, we tested the representativeness of our results by comparing LPJmL results with comparable data from other models. Specifically, we compared the forest sink due to indirect effects from LPJ-mL with the results from eight DGVMs for the period 2005-2014 and with the latest available data in the ISIMIP database up to 2100 (https://www. isimip.org/), and the whole land sink from LPJmL with comparable data in the IPCC Fifth Assessment Report ${ }^{69}$. Based on these comparisons, we conclude that the forest and whole land sinks in LPJmL are reasonably representative of the available data in the literature (Supplementary Section 5).

\section{Data availability}

The vast majority of data used in this study are included in the Supplementary Information (for example, from NGHGIs) or on public websites (for example, the SSP database for IAMs). Any other data that support the findings of this study are available from the corresponding author upon request.

\section{References}

54. Transparency and Reporting (UNFCCC, accessed 20 February 2021); https:// unfccc.int/process-and-meetings/transparency-and-reporting/the-big-picture/ what-is-transparency-and-reporting

55. National Inventory Submissions (UNFCCC, accessed 20 February 2021); https://unfccc.int/ghg-inventories-annex-i-parties/2020

56. Nationally Determined Contributions (UNFCCC, accessed 20 February 2021); https://unfccc.int/nationally-determined-contributions-ndcs

57. National Communications Non-Annex I (UNFCCC, accessed 20 February 2021); https://unfccc.int/non-annex-I-NCs

58. Biennial Update Reports Non-Annex I (UNFCCC, accessed 20 February 2021); https://unfccc.int/BURs

59. REDD+ Submissions (UNFCCC, accessed 20 February 2021); https://redd. unfccc.int/submissions.html

60. Federici, S. et al. GHG Fluxes from Forests: An Assessment of National GHG Estimates and Independent Research in the Context of the Paris Agreement (Climate and Land Use Alliance, 2017); http://www. climateandlandusealliance.org/reports/ghg-fluxes-forests/

61. IPCC Good Practice Guidance for Land Use, Land-Use Change and Forestry (eds Penman, J. et al.) (Institute for Global Environmental Strategies, 2003).

62. Ogle, S. M. et al. Delineating managed land for reporting national greenhouse gas emissions and removals to the United Nations framework convention on climate change. Carbon Balance Manag. 13, 9 (2018).

63. Forsell, N. et al. Assessing the INDCs' land use, land use change, and forest emission projections. Carbon Balance Manag. 11, 26 (2016).

64. van Vuuren, D. P. et al. A new scenario framework for climate change research: scenario matrix architecture. Climatic Change 122, 373-386 (2014)

65. Rogelj, J. et al. Scenarios towards limiting global mean temperature increase below $1.5^{\circ} \mathrm{C}$. Nat. Clim. Change 8, 325-332 (2018).

66. Stehfest, E. et al. Integrated Assessment of Global Environmental Change with IMAGE 3.0-Model Description and Policy Applications Report 07-07-2014 (PBL Netherlands Environmental Assessment Agency, 2014).

67. Arets, E. J. M. M. et al. Global Wood Production. Assessment of Industrial Round Wood Supply from Forest Management Systems in Different Global Regions Report 1808 (Alterrah, 2011). 
68. Pan, Y. et al. A large and persistent carbon sink in the World's forests. Science 333, 988-993 (2011).

69. IPCC Climate Change 2013: The Physical Science Basis (eds Stocker, T. F. et al.) (Cambridge Univ. Press, 2013).

\section{Acknowledgements}

G.G. acknowledges funding from the EU's Horizon 2020 VERIFY project (no. 776810) J.R. acknowledges funding from the EU's Horizon 2020 CONSTRAIN project (no. 820829). F.H. and D.v.V. acknowledge funding from the EU's Horizon 2020 ENGAGE project (no. 821471). S. Fujimori and T.H. were supported by the Environment Research and Technology Development Fund (JPMEERF20202002) of the Environmental Restoration and Conservation Agency of Japan and the Sumitomo Foundation. F.N.T. was supported by regular programme funding by member states to FAO. FAOSTAT and FRA are made possible through country data reporting processes to FAO and contributions of experts in the member states. The views expressed are purely those of the writers and may not under any circumstances be regarded as stating an official position of the European Commission, FAO or any other institution.

\section{Author contributions}

G.G. led the study design with the help of E.S., J.R., A.P., D.v.V., A.C. and J.H., wrote the first draft, performed the analysis and created the figures; J.R. and E.S. refined the draft paper, along with A.P., D.v.V., G.-J.N. and A.K.; E.S. provided the IMAGE/LPJmL data, which were combined with non-intact forest maps by S.R. supported by G.C.; S. Federici, R.A.V. and A.K. helped in the analysis of country GHG inventories. IAM data were provided and checked by S. Fujimori and T.H. (AIM/CGE), K.C. (GCAM), E.S. and D.v.V. (IMAGE), M.G. and P.H. (MESSAGE-GLOBIOM), F.H. and A.P. (REMIND-MAgPIE). F.N.T. provided FAOSTAT data and contributed to their analysis. All the authors provided feedback and contributed to writing the article.

\section{Competing interests}

The authors declare no competing interests.

\section{Additional information}

Extended data is available for this paper at https://doi.org/10.1038/s41558-021-01033-6. Supplementary information The online version contains supplementary material available at https://doi.org/10.1038/s41558-021-01033-6.

Correspondence and requests for materials should be addressed to G.G.

Peer review information Nature Climate Change thanks Claire Fyson and the other, anonymous, reviewer(s) for their contribution to the peer review of this work.

Reprints and permissions information is available at www.nature.com/reprints. 


\begin{tabular}{|c|c|c|c|c|c|c|c|c|c|}
\hline & & & & & Area & IAMs & DGVMs & NGHGls & $\begin{array}{l}\text { Hansen / } \\
\text { Potapov }\end{array}$ \\
\hline & & & & & Managed & 1 & & 3 & \\
\hline & & & & & Unmanaged & 3 & & 1 & \\
\hline & est & rea & Billion & & $\begin{array}{l}\text { Non-intact } \\
\text { forest }\end{array}$ & & & & 3 \\
\hline & & & & & Intact forest & & & & 1 \\
\hline & & & & & $\begin{array}{l}\text { Total forest } \\
\text { area }\end{array}$ & 4 & & 4 & 4 \\
\hline & & & $\begin{array}{l}\text { xes th } \\
\text { est-rel }\end{array}$ & are not & & $+1^{\mathrm{b}}$ & & $+0^{\mathrm{b}}$ & \\
\hline & $\underset{\mathscr{0}}{\stackrel{\oplus}{\Phi}}$ & & Defo & station & area & $+5^{c}$ & & $+5^{c}$ & \\
\hline & 造 & ڤँ & $\begin{array}{l}\text { Fore } \\
\text { regro }\end{array}$ & $\begin{array}{l}\text { harvest, } \\
\text { h after }\end{array}$ & & $\left(-1^{d}\right)$ & & & \\
\hline$\stackrel{\mathbb{\Phi}}{\perp}$ & & & & & & & & (managed & \\
\hline Oे & & & & & $\begin{array}{l}\text { Non-intact } \\
\text { forest }\end{array}$ & & -5 & & \\
\hline$\underbrace{0}_{0}$ & & 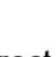 & ff & & Intact forest & & -2 & & \\
\hline$\stackrel{x}{\underline{\underline{x}}}$ & & & & & $\begin{array}{l}\text { Non-forest } \\
\text { land }\end{array}$ & & -3 & estimated & \\
\hline & & & & & All area & & -10 & & \\
\hline & & & & $\begin{array}{l}\text { Sum of } \\
\text { direct effects }\end{array}$ & $\begin{array}{l}\text { IAMs' } \\
\text { managed }\end{array}$ & +5 & & $\begin{array}{c}\text { not } \\
\text { estimated }\end{array}$ & \\
\hline & & flux & IT & $\begin{array}{l}\text { NGHGI- } \\
\text { compatible }\end{array}$ & $\begin{array}{l}\text { Countries' } \\
\text { managed }\end{array}$ & $\begin{array}{l}\text { (direct eff } \\
\text { effects in } n\end{array}$ & $\begin{array}{l}\text { irect } \\
\text { orest) }\end{array}$ & 0 & \\
\hline
\end{tabular}

a Approximate values from Fig. 3b.

b Fluxes that are not forest-related include cropland, managed grassland, managed wetland, etc. Approximate values from IAMs and NGHGI (see Supplementary table 4). In many developing countries, the NGHGI reporting of these fluxes is incomplete.

${ }^{\mathrm{c}}$ Approximate values from Fig. $1 \mathrm{~b}$.

${ }^{\mathrm{d}}$ Inferred as difference between net anthropogenic flux (last row) and emissions from not forest-related fluxes and deforestation.

e See Fig. 5a-c

Extended Data Fig. 1 | Summary of the selected components of land $\mathrm{CO}_{2}$ fluxes in IAMs, DGVMs and NGHGIs, and areas of managed and unmanaged forest and of intact and non-intact forest ${ }^{28,52}$. Values are approximated (broadly based on the averages for 2005-2015) with the purpose to illustrate where the main differences are between IAMs and NGHGIs, that is not much on direct effects, but rather on how indirect effects are estimated and labelled (if anthropogenic or not). As a result, when considering a broadly similar area of forest (that is about 3 billion ha of non-intact forest), the sum of $\mathrm{CO}_{2}$ fluxes by global models (IAMs and DGVMs) match well those from NGHGIs. Numbers in parenthesis indicate values not included in the original IAM and NGHGI datasets, but estimated here (see footnotes). 